\title{
MRI in Rodent Models of Brain Disorders
}

\author{
Aleksandar Denic, ${ }^{1}$ Slobodan I. Macura, ${ }^{2}$ Prasanna Mishra, ${ }^{2}$ Jeffrey D. Gamez, ${ }^{3}$ \\ Moses Rodriguez, ${ }^{3}$ and Istvan Pirko ${ }^{3}$ \\ ${ }^{I}$ Department of Neuroscience; ${ }^{2}$ Department of Biochemistry and Molecular Biology, and ${ }^{3}$ Department of Neurology, Mayo Clinic, \\ 200 First St. SW, Rochester, Minnesota 55905
}

Summary: Magnetic resonance imaging (MRI) is a wellestablished tool in clinical practice and research on human neurological disorders. Translational MRI research utilizing rodent models of central nervous system (CNS) diseases is becoming popular with the increased availability of dedicated small animal MRI systems. Projects utilizing this technology typically fall into one of two categories: 1) true "pre-clinical" studies involving the use of MRI as a noninvasive disease monitoring tool which serves as a biomarker for selected aspects of the disease and 2) studies investigating the pathomechanism of known human MRI findings in CNS disease models. Most small animal MRI systems operate at 4.7-11.7 Tesla field strengths. Although the higher field strength clearly results in a higher signalto-noise ratio, which enables higher resolution acquisition, a variety of artifacts and limitations related to the specific absorption rate represent significant challenges in these experiments. In addition to standard T1-, T2-, and T2*-weighted MRI methods, all of the currently available advanced MRI techniques have been utilized in experimental animals, including diffusion, perfusion, and susceptibility weighted imaging, functional magnetic resonance imaging, chemical shift imaging, heteronuclear imaging, and ${ }^{1} \mathrm{H}$ or ${ }^{31} \mathrm{P} \mathrm{MR}$ spectroscopy. Selected MRI techniques are also exclusively utilized in experimental research, including manganese-enhanced MRI, and cell-specific/molecular imaging techniques utilizing negative contrast materials. In this review, we describe technical and practical aspects of small animal MRI and provide examples of different MRI techniques in anatomical imaging and tract tracing as well as several models of neurological disorders, including inflammatory, neurodegenerative, vascular, and traumatic brain and spinal cord injury models, and neoplastic diseases. Key Words: Small animal MRI, mouse model, rodent model, brain disorders, MRI.

\section{INTRODUCTION}

Animal models are frequently used in the study of various central nervous system (CNS) disorders, such as vascular, inflammatory, neurodegenerative, and neoplastic diseases. These disease models may represent either selected aspects or, occasionally, the full spectrum of the corresponding human disease. Mouse colonies are relatively easy to maintain, and the universal availability of transgenic animals coupled with the capability of generating new, genetically modified mice from wellcharacterized "standard" strains represents a major advantage in identifying and exploring pathogenic mechanisms relevant to CNS diseases.

Electronic supplementary material The online version of this article (doi:10.1007/s13311-010-0002-4) contains supplementary material, which is available to authorized users.

Address correspondence and reprint requests to: Istvan Pirko, M.D., Department of Neurology, Mayo Clinic, 200 First St. SW, Rochester, MN 55905. E-mail: pirko@mayo.edu.
One of the most common approaches in biomedical research is to visualize tissue compartments or cellular interactions in various tissues. In this context, standard optical microscopy has two major limitations: 1) only ex vivo tissues can be studied at high resolution and 2) the degree of specificity varies depending on the staining method used. Newer intravital microscopy techniques are also emerging and have become very useful tools for in vivo monitoring of cellular motion and cell-cell interactions. The main advantages of intravital microscopy are high microscopic resolution, multiplex and real-time imaging with good image quality, and the capability of tracking of various labeled cell types. However, there are also limitations, including the required surgical window, smaller field of view, and limited tissue penetration.

Because most disease processes are dynamic, noninvasive in vivo imaging modalities are of great advantage as they allow for investigations to be performed at multiple different time points. Small animal magnetic resonance imaging (MRI) studies are usually preclinical: they establish or study new aspects of a disease process 
that have not yet been clarified in the human disease. Small animal MRI also allows for translational projects in which the pathomechanism of human MRI findings are studied. The first report of MR imaging of a rat was published over 30 years ago [1]. MRI has the capability of studying live organisms without exposing them to potentially harmful ionizing radiation. Besides anatomical imaging, MRI is also capable of providing physiological information about several important aspects of biological processes, including circulation and cerebrospinal fluid flow, cerebral blood flow and volume, activity mapping with functional MRI (fMRI) or $\mathrm{Mn}^{++}$-based techniques, metabolite distribution with chemical shift imaging, diffusion or perfusion properties of the studied tissue, or in vivo $\mathrm{pH}$ measurement via phosphorus MR spectrometry (MRS) [2, 3].

\section{TECHNICAL ASPECTS OF SMALL ANIMAL MRI}

Many universities and research institutions have acquired small animal MR imaging systems, most commonly as part of a core facility. Most research facilities use 4.7- to 11.7-Tesla (T) narrow-bore magnets, of which the $7 \mathrm{~T}$ magnet is the most commonly utilized. The two leading manufacturers of these systems are Bruker Biospin (Ettlingen, Germany) and Varian Medical Systems (Palo Alto, CA). Both vertical and horizontal bore systems are available. Vertical bore neutron magnetic resonance spectrometers equipped with gradient coils and imaging probes are the most common systems used in biochemistry-based core facilities, whereas in radiology research facilities, horizontal bore magnets are more common. Obviously, the physical principles remain the same regardless of the orientation of the bore. However, the horizontal bore system often allows for easier monitoring of the mice and larger flexibility in customizing the probes and coils. Most facilities employ their own engineers and technicians. Larger facilities often develop not only their own pulse sequences and post-processing software tools, but also design hardware, including radio frequency (RF) coils and rodent head stabilizing probes. Most commonly, only the field strength is mentioned when the differences between imaging systems is discussed. However, the utilized RF and gradient coils are equally important and can literally determine the success of an experimental MRI research program. Custom-made coils specific to the studied research question often have a significantly better signal-to-noise ratio (SNR) than stock coils.

While MR image acquisition is a very complex process, image analysis is often far more time consuming and computation intense. Image processing and visualization tools are included with the software provided by the scanner manufacturer, but they are generally insufficient to provide the desired detailed answers. Several commercially available biomedical image post-processing software packages are available, and many research institutions develop their own software applications. Notable examples of image analysis software are Analyze [4, 5], Statistical Parametric Mapping [6], the freely downloadable National Institutes of Health image [7, 8], and Analysis of Functional NeuroImages [9]. Most of these provide basic analysis methods, including intensity and region of interest-based area or volume measurements. They also include tools for slice extraction from 3-dimensional (3D) volumes and for a variety of 3D visualizations. Several offer segmentation, coregistration, and other tools for complex analyses requiring image algebra methods, including diffusion tensor imaging (DTI) visualization, perfusion calculations, or fMRI visualization tools.

\section{SPECIAL REQUIREMENTS FOR SMALL RODENT MRI}

MRI requires the study subjects to be completely immobilized, and the importance of this cannot be stressed enough. In order to achieve this goal, general anesthesia (in most cases, inhalational) must be used in small animal experiments [10]. Unlike injectable agents, inhalational anesthesia is administered continuously and can be calibrated to the specific requirements posed by the animal and the experiment. The anesthesia may in some cases alter the studied biological processes and/or the desired imaging outcome. This is especially true for cerebral blood flow/blood volume and fMRI studies [11]. Animal monitoring under anesthesia is also an important requirement and includes monitoring of core temperature, respiratory rate, and electrocardiogram. Oxygen saturation and $\mathrm{CO}_{2}$ level monitors are also available. Monitoring is also important from the standpoint of gated acquisition, which is often needed to eliminate respiration or cardiac motion-related artifacts during acquisition. The most commonly used systems are manufactured by SA Instruments (Stony Brook, NY; http://www.i4sa.com/).

The core temperature inside narrow-bore scanners can be in the low $50^{\circ} \mathrm{F}$ range $\left(15-20^{\circ} \mathrm{C}\right)$, and various heating systems are utilized to maintain the normal core temperature of the animals while in the scanner. These are usually supplied by the imaging systems vendors. Most utilize either warm airflow or circulating water beds.

In addition to the anesthesia and maintaining a suitable core temperature, another important factor in successful small rodent MRI is that the probe should keep the animal stable during the imaging session [12]. Most small animal systems are shipped with mouse and rat probes, but many laboratories develop custom-made holders for specific applications and/or for added stability. A good probe should achieve maximal stabili- 

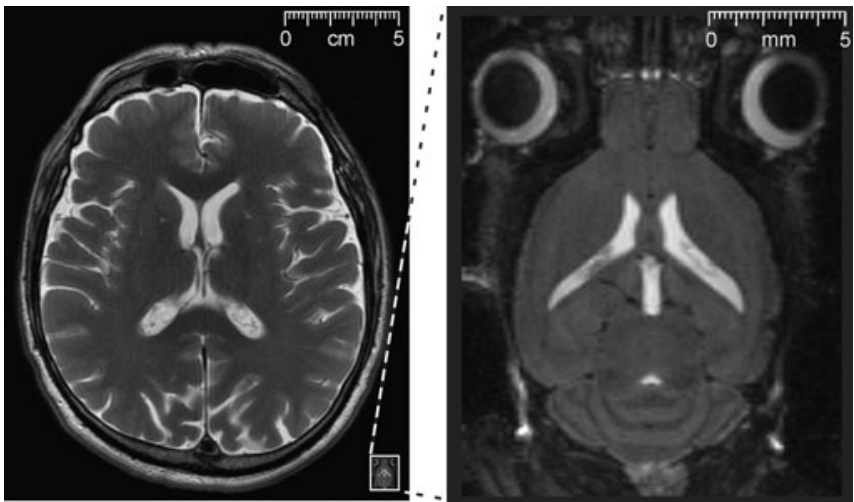

FIG. 1. Comparison of magnetic resonance imaging (MRI) scans of a human (left) versus mouse (right) brain. Parameters of the clinical MR image: Field of view (FOV), $22 \times 22 \mathrm{~cm}^{2}$; matrix size, $256 \times 256$; slice thickness, $4 \mathrm{~mm}$. The mouse MR image was extracted from a $3-$ dimensional dataset with parameters: FOV, $3.2 \times 1.92 \times 1.92 \mathrm{~cm}^{3}$; matrix size, $256 \times 128 \times 128$. The entire mouse brain is about the size of the human caudate nucleus head. (High resolution version of this image is available in the electronic supplementary material.)

zation without any trauma to the animal. Ideal animal holders should also allow for easily reproducible stereotactic placement.

\section{DIFFERENCES BETWEEN SMALL ANIMAL IMAGING AND HUMAN MRI: ADVANTAGES AND DISADVANTAGES OF THE HIGHER FIELD STRENGTH}

The study of experimental animals with MRI differs in more ways than just the smaller scale that rodent imaging requires. However, the smaller scale (of a mouse CNS) itself is a major problem to overcome (FIG. 1) Most small animal magnets operate at a high field strength, namely, in the range of 4.7-11.7T, as opposed to the standard clinical range of 1.5-3T. The main advantage of high field scanners is the increased SNR (FIG. 2); at the same time, increased image artifacts and other limitations make higher field strength scanning technically more challenging. In living organisms, which are comprised of multiple compartments with different physico-chemical properties, artifacts can be generated due to susceptibility and different relaxation properties at the higher field strength [13]. Why certain imaging artifacts are more prominent at the very high field strengths utilized can be
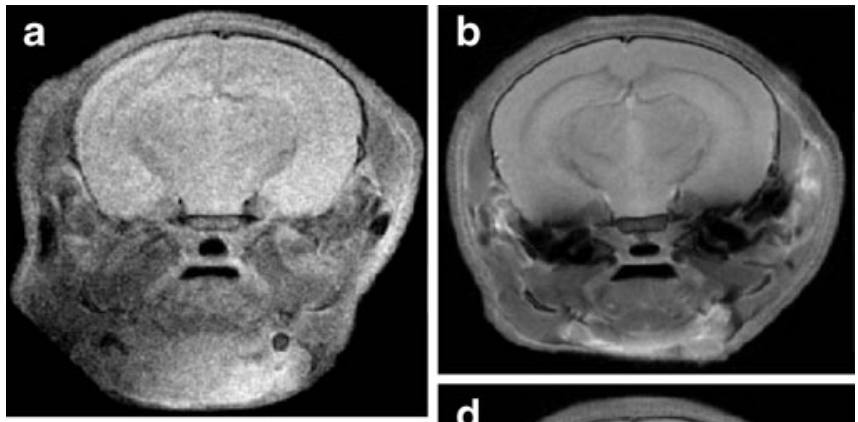

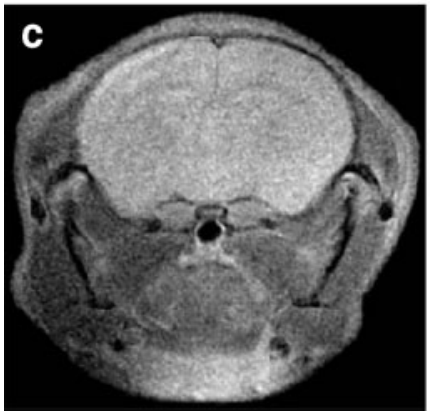

7 Tesla

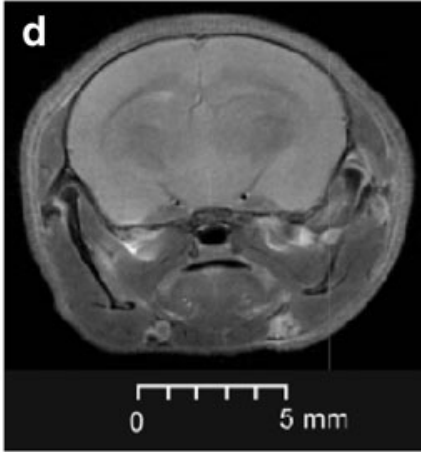

16.4 Tesla

FIG. 2. 7 Teslar $(\mathrm{T})(300 \mathrm{MHz})(\mathrm{a}, \mathrm{c})$ versus $16.4 \mathrm{~T}(700 \mathrm{MHz})(\mathrm{b}, \mathrm{d})$ images of the same live mouse. Spin echo [turbo-rapid acquisition relaxation enhancement (RARE)] images of 1-mm-thick slices were obtained using transmission time $(T R)=4 \mathrm{~s}$, echo time $(T E)=14.7 \mathrm{~ms}$, RARE factor $=4$, number of averages $=8$, total scanning time $=34 \mathrm{~min}$. The in-plane isotropic image resolution is $59 \mu \mathrm{m} /$ pixel. Note the much higher signal-to-noise ratio (SNR) in the 16.4T MR images (b, d), as well as stronger susceptibility artifacts in (b). (High resolution version of this image is available in the electronic supplementary material.) 
best understood in the context of the well-known scaling relationships that describe how SNR, chemical shift, susceptibility variation, specific absorption rate, and RF wavelength vary with increased field strength (Table 1). Each artifact that is seen at 4.7-11.7T can also be seen at 1.5-3T-but not as prominently. Some artifacts are related to the hardware, including spike-noise artifacts, $\mathrm{RF}$ interference artifacts (crosstalk between the RF transmit and receive channels, RF penetration due to magnet room shielding issues, especially for vertical bore magnets), and central dot artifacts. Artifacts that are typically more prominent due to increased SNR include aliasing (wraparound) artifacts (also prominent at lower field strengths), Gibbs ringing (truncation artifact), fine line artifact [particularly common in rapid acquisition relaxation enhancement (RARE) sequences], and half field-of-view ghosting (especially with parallel acquisition). Chemical shift- and susceptibility-related artifacts are especially common at high field strengths. Relaxation time effects also need to be considered: the $\mathrm{T} 1$ relaxation time of many tissues increases by $20-50 \%$ between 1.5 and $3 \mathrm{~T}$, while the $\mathrm{T} 2$ relaxation time is generally unchanged, although the apparent $\mathrm{T} 2 *$ relaxation time decreases in most tissues. It is good practice to conduct relaxometry experiments in the tissue compartments of interest to sort out these issues in the given system. The specific absorption rate is a key limiting factor at higher field strengths for in vivo experiments. Novel pulse sequences and/or changes in acquisition parameters in an effort to minimize RF power levels are needed to allow for image acquisition without potentially dangerous energy absorption and related heating of the tissue.

Most investigators would like to obtain image sets of excellent resolution and high SNR within a very short space of time. Each of the above three components (SNR, resolution, imaging time) are interdependent. For example, the price one pays for a good SNR is frequently a lower resolution and/or longer acquisition time. Or, if both good SNR and resolution are the goals, then the imaging time usually is prolonged. Finding an acceptable

Table 1. The Scaling of Key Physical Parameters with the Strength of the Main Magnetic Field $B_{0}$.

\begin{tabular}{|c|c|}
\hline Physical parameter & Dependence on $B_{0}$ \\
\hline Signal-to & Linear: SNR $\alpha B_{0}$ \\
\hline $\begin{array}{l}\text { Frequency offset due to } \\
\text { susceptibility variation (in } \mathrm{Hz} \text { ) }\end{array}$ & Linear: \\
\hline Chemical shift (C.S.) (in Hz) & Linear: C.S. $\alpha \mathrm{B}_{0}$ \\
\hline $\begin{array}{l}\text { Specific absorption rate } \\
\text { (SAR) (in W/kg) }\end{array}$ & Quadratic: SAR $\alpha$ \\
\hline $\begin{array}{l}\text { Ratio frequency (RF) } \\
\text { wavelength (in m) }\end{array}$ & Inverse: $\lambda \alpha 1 /\left(B_{0} \sqrt{\varepsilon_{r}}\right)$ \\
\hline
\end{tabular}

The relationships for the SNR and SAR hold fairly well in the range of currently utilized field strengths. The relative permittivity $\varepsilon_{\mathrm{r}}$ itself can vary with RF, and hence $B_{0}$.

Modified from S.S. Kannurpatti and B. B. Biswal [11] with permission. balance may be a difficult task. Several parameters of the studied model should be considered when the goal is to optimize image acquisition.

Living organisms can be considered inhomogeneous samples, with compartmentalized organs containing solid, gaseous, and various consistencies of liquid (from fluid to gelatinous) substances. These different consistencies have different magnetic susceptibilities, and whereas this in general does not represent a major problem at lower field strength, it becomes a very important problem at the higher field strength. Magnetic susceptibility is a known source of artifacts. One of the best examples for susceptibility artifacts is the loss of brain signal near air-filled sinuses. Gradient echo-based sequences are especially prone to these artifacts. Several methods have been proposed to reduce these artifacts, including the GESEPI sequence $[14,15]$. In gradient echo imaging, slice selection correction methods have also been tried and successfully used [16, 17]. For multislice studies, the use of phase-phase encoding is helpful in reducing susceptibility-related artifacts. Sequences that use RF refocused echoes (fast spin echo, or rapid acquisition with refocused echo) [18], which are variants of spin echo sequences, eliminate most of the susceptibility-related artifacts. However, in some applications, susceptibility-related artifacts might be of benefit. The blood oxygen level-dependent (BOLD) signal (described later in this review) - the basis of fMRI studies - and iron oxide-based negative contrast agents [superparamagnetic iron oxides (SPIOs)] are good examples for this.

Susceptibility-weighted imaging (SWI) is another novel method that takes advantage of different magnetic susceptibilities of tissues, and represents a new tool to enhance tissue contrast [19-21]. This method is based on relative differences between the magnetic susceptibility in one tissue and the surrounding tissue or a background. At long echo times (TE), signals from two tissues that have different magnetic susceptibilities will be out of phase and obtaining the phase images is the crucial point that defines the contrast in these experiments [21]. SWI is a very convenient tool in assessing the iron content or any other substance that distorts the local field [22]. SWI was initially utilized mostly as a method for MR venography procedures [23-26], but more recently this method has found its place in studying arterial venous malformations [27, 28], hemorrhagic lesions [29], brain tumors [30, 31], and multiple sclerosis (MS) [32].

\section{COMMON MRI METHODS IN STUDIES OF CNS DISEASE MODELS}

\section{Anatomical/structural imaging}

Several neurological disease models have been studied using small animal MRI systems. The greatest advantage 
of the numerous MRI methods utilized in small animal research is that they are performed noninvasively and allow anatomical, pathological, and functional information to be obtained repeatedly over time. One of the most basic applications is to generate 3D anatomical atlases of rodent brains. This has been accomplished by several groups [33-36]. Similarly, MRI atlases describing mouse embryonic development have also been generated and reported [37]. A web-based application assembled by the California Institute of Technology allows insight into one of these databases [38, 39]. An example of high-resolution ex vivo anatomical imaging is shown in FIG. 3.

\section{MRI-based tractography}

In basic neuroscience research, tract tracing via MRI is an important and still under-utilized application. While DTI-based techniques allow for fiber visualization based on physical properties of the studied CNS tissue, manganese-enhanced MRI (MEMRI) allows for investigations of actual tracts and their synaptic connections. This technique utilizes paramagnetic $\mathrm{Mn}^{++}$ions. In MRI, $\mathrm{Mn}^{++}$ions cause a shortening of the water $\mathrm{T}_{1}$ relaxation time with strong contrast enhancement in $\mathrm{T}_{1}$-weighted MRI [40]. Having similar chemical properties as $\mathrm{Ca}^{++}$, $\mathrm{Mn}^{++}$ions are actively taken up by neurons via voltagegated $\mathrm{Ca}^{++}$channels [41]. Once inside the neurons, they can pass the $\mathrm{Mn}^{++}$ions to each other via the synaptic junctures, thus allowing visualization of neural pathways by MRI [42-45]. It is thought that $\mathrm{Mn}^{++}$ions enter the cells due to the opening of receptor-activated calcium channels. Once inside the cell, $\mathrm{Mn}^{++}$ions utilize axonal microtubule transport mechanisms to reach the axon terminal. During synaptic transmission, $\mathrm{Mn}^{++}$is released from the presynaptic neuron. It is able to enter the postsynaptic neuron via calcium channels [43]. Thus, $\mathrm{Mn}^{++}$ions will accumulate in activated chains of neurons, leading to increased signal intensity in activated parts of the CNS. If applied topically to areas of interest from the standpoint of their connectivity, such as cortical areas and olfactory neurons, or to the retina, then $\mathrm{Mn}^{++}$can be used for tract tracing [45-48]. Bilgen et al. [46] used MEMRI to visualize injected $\mathrm{Mn}^{++}$ions in normal and hemisected spinal cords in rats. They also suggested MEMRI as a method for indirect assessment of axonal integrity and connectivity of corticospinal tract in injured rat spinal cords [47]. An example of MEMRI is shown in FIG. 4 [49].

\section{Functional MRI studies}

Functional MRI studies are also conducted in small rodents. fMRI studies are based on the BOLD principle. Blood flow and oxy/deoxyhemoglobin-related changes in activated areas of the cortex produce mild hypointensity on $\mathrm{T} 2 *$ images [50-53]. Images obtained in the activated and nonactivated state are used to generate activity maps, including sensory or visual cortex mapping in animals $[50,54]$. Mild hypocapnia may be helpful in establishing BOLD contrast [55]. Some rodent fMRI studies have

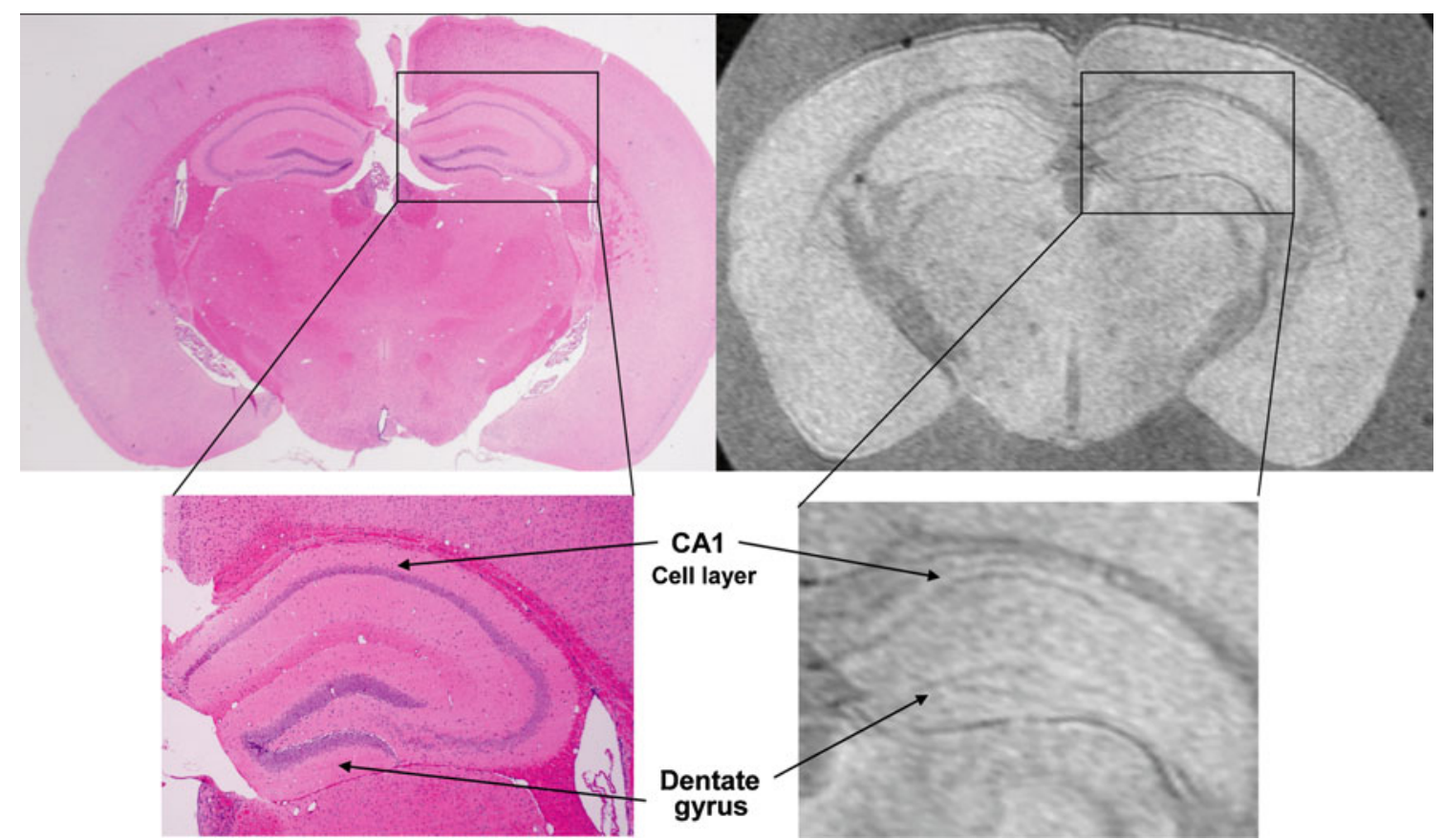

FIG. 3. $16.4 \mathrm{~T}(700 \mathrm{MHz}) \mathrm{MR}$ microscopy of ex vivo mouse brain (right) compared to histological section stained with hematoxylin/eosin (left). Note the excellent anatomical resolution of the CA1 cell layer in the hippocampus and dentate gyrus on the right image extracted from an MRI 3D dataset. The high SNR and high isotropic resolution $(55 \mu \mathrm{m} / \mathrm{pixel})$ are achieved at the expense of long scanning time $(5 \mathrm{~h}$ and $27 \mathrm{~min}$ ). Other parameters: FOV, $14 \times 14 \times 14 \mathrm{~mm}^{3}$; matrix size, $256 \times 256 \times 256$; TR=400 ms; TE=7 ms. (High resolution version of this image is available in the electronic supplementary material.) 


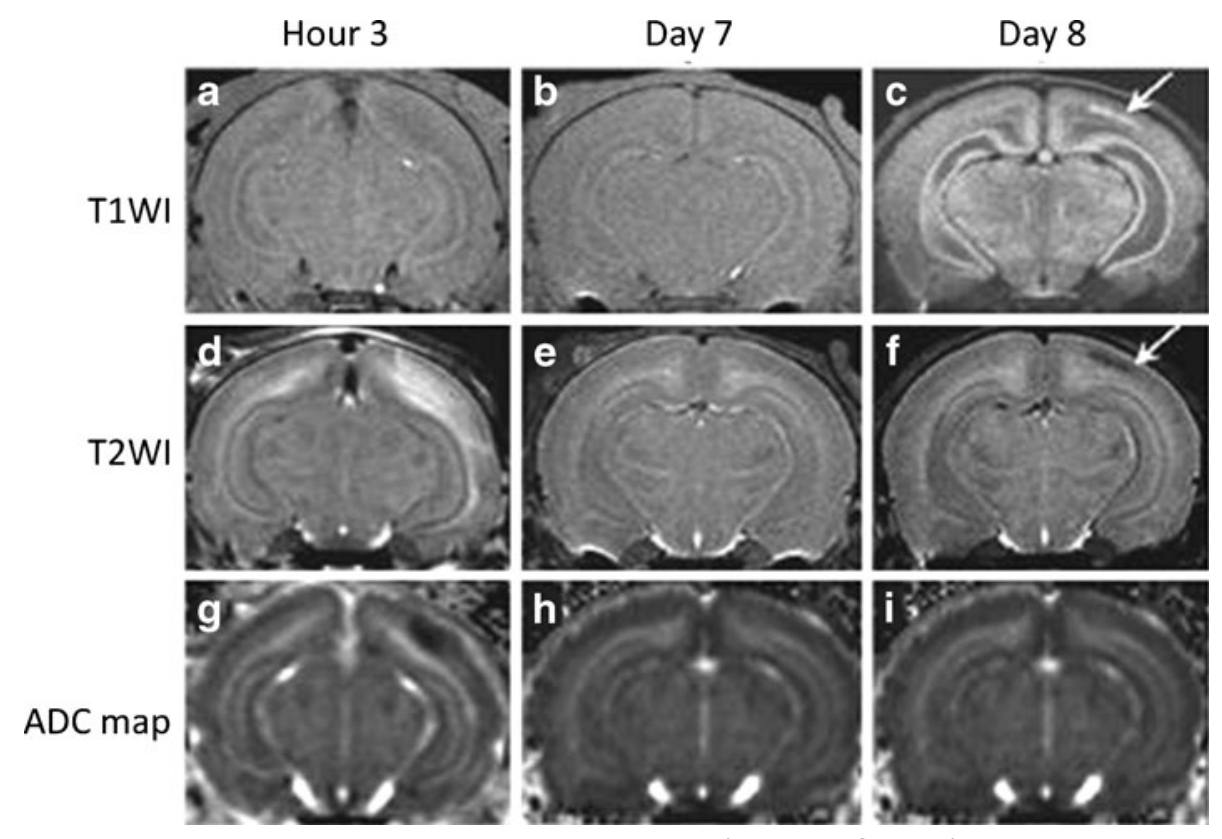

FIG. 4. Typical gray matter lesion in a rat model of hypoxic-ischemic injury (arrows in $C$ and $F$ ) was observed in late phase by manganese-enhanced MRI (MEMRI) after $\mathrm{Mn}^{++}$injection on day 7, which was not visible in the T2WI, T1WI, and ADC map (Reproduced with permission from J. Yang and E.X. Wu [49]). T2WI = T2-weighted MR image, T2WI =T2-weighted MR image, ADC = apparent diffusion coefficient. Reproduced with permission from the Institute of Electrical and Electronics Engineers (IEEE). (High resolution version of this image is available in the electronic supplementary material.)

also utilized SPIO/ultrasmall (US)PIO contrast materials to enhance signal loss at the activated areas [51]. These techniques also allow the measurement of cerebral blood volume [51, 56, 57]. One recent fMRI study was the first such study to successfully utilize thermal stimuli to distinguish the noxious and innocuous pathways in the rat spinal cord [58]. Another group demonstrated an fMRI method with simultaneous acquisition of rat brain and spinal cord images [59]. These researchers proposed that the simultaneous brain and spinal cord fMRI can be used not only in animal models, but also in several neurological disorders in humans, such as MS, movement disorders, brain trauma, and spinal cord injuries, among others.

\section{Cell-specific and molecular MRI}

Cell-specific and molecular MRI is now used in the study of several disease models [60-62]. These techniques are important tools for establishing a better correlation between conventional histology and MRI methods. Many groups have reported success with immune cell-specific imaging, utilizing superparamagnetic contrast materials (SPIOs) that are either internalized by cells after in vitro incubation or bound to the cells by specific antibodies (FIG. 5) [60, 62-66]. SPIOs are detectable through their property of generating strong susceptibility effects (shortening of $\mathrm{T} 2 *$ relaxation) as well as shortening of the $\mathrm{T} 1$ and $\mathrm{T} 2$ relaxation time. Since susceptibility artifacts are

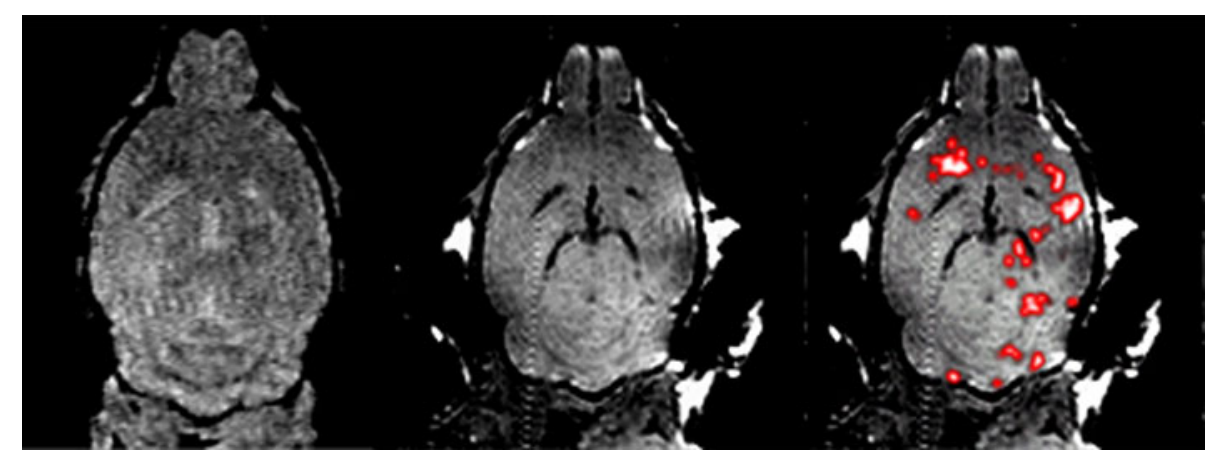

FIG. 5. $\mathrm{CD}^{+}$T-cell labeling with ultrasmall superparamagnetic iron oxide (USPIO)-conjugated antibodies in Theiler's murine encephalomyelitis virus infection. Left image: $2^{*}$-weighted image shows diffuse hypointensities in several areas of the cerebrum and cerebellum. Middle image: T1-weighted study shows faint hyperintense areas. Right image: composite image, using a mask generated by dividing the T1-weighted image matrix with the T2* weighted. Reproduced with permission from I. Pirko et al. [150]. (High resolution version of this image is available in the electronic supplementary material.) 
stronger at high field strengths, these contrast materials are especially suitable for small animal imaging. The SPIOs include standard SPIOs (size, usually 50-150 nm), USPIOs (size, 30-50 nm) [67] and micron-sized paramagnetic iron oxide (MPIO) (size, approaching or more than $1 \mu \mathrm{m}$ ) [68]. The first use of SPIOs as a contrast agent was in liver and splenic tumor imaging [69, 70]. As a cellular label, SPIOs are used for MR cell tracking, as in detecting the specific locations of inflammation [71] or macrophage infiltration [72] in experimental autoimmune encephalomyelitis (EAE), the most widely used murine model of MS. Subsequently, USPIOs with a longer blood half-life were developed and utilized for the imaging of macrophage infiltration in the brains of animals with EAE [73-75]. Several groups have investigated the effects of particle size and iron concentration on SPIO and USPIO uptake rates. In comparison with USPIOs, macrophages and monocytes appear to have much a higher uptake preference for SPIOs and are more effectively labeled by the latter [76, 77]. Thorek et al. [78] tested the uptake rate of different sized SPIOs in non-phagocytic T-cells and showed that particles $<300 \mathrm{~nm}$ were most efficient in cell labeling. Even though USPIOs provide less contrast enhancement and SPIOs may be more efficient and suitable for macrophage labeling, USPIOs are overall preferred due to 1) longer blood half life ( $>24 \mathrm{~h}$ ) and 2) larger number of particles loaded per cell [79]. One potential application of similar USPIO-based labeling techniques is to follow the distribution of biologically active proteins [60]. More recently, McAteer et al. [80] reported a molecular imaging methodology utilizing MPIOs. By utilizing antibody conjugated MPIOs, they showed clear upregulation and activation of Vascular Cell Adhesion Molecule 1 in a model of acute brain inflammation. In addition to the above labeling methods, "smart" molecular imaging probes and "sensing" contrast agents that are activated at specific sites of interest by enzymatic modification represent an interesting avenue for future development [81, 82].

\section{MRI STUDIES OF COMMON CNS DISEASE CATEGORIES}

\section{Inflammatory diseases of the CNS}

Inflammatory and demyelinating diseases of the CNS are frequently studied in animal models. The most common models include EAE, Theiler's murine encephalitis virus infection TMEV), and toxic demyelination models. A successful in vivo DTI of the spinal cord in mice with EAE has been reported [83] and proposed as a potential surrogate marker of axonal and myelin damage in this model. The authors demonstrated that relative anisotropy was a very sensitive biomarker to detect white matter destruction in EAE-affected mice, whereas the
ADC was not. Similar to human diseases, lesion formation can be monitored by T2-weighted sequences (FIG. 6). Moreover, classical high resolution T2weighted MRI may be used to investigate volumetric changes in brains of EAE mice as well as to correlate with subsequent histopathological analysis [84]. The presence of deep gray matter T2 hypointensity was recently demonstrated in the TMEV model with strong functional correlations [85]. A combination of gadolinium (Gd)-enhanced $\mathrm{T} 1-$ with $\mathrm{T} 2-$ and $\mathrm{T} 2{ }^{*}$-weighted imaging was used to characterize a new animal model of an acute hemorrhagic leuko-encephalomyelitis, a rare and fatal neurological disorder in humans [86]. Toxininduced demyelination is less frequently studied by MRI. T2W imaging together with diffusion-weighted imaging (DWI) has been demonstrated to be useful in studying patterns of corpus callosum demyelination in cuprizone fed mice, a toxic model of MS [87]. In the same toxic model, both the magnetization transfer ratio [88] and DTI [89] were proposed to serve as sensitive and reproducible surrogate markers in quantifying myelin loss and repair.

Gd enhancement is used to monitor the blood-brain barrier permeability associated with new lesion formation [90]. Measurements of brain atrophy are important for assessing the chronic aspects of many neurological diseases. Volumetric MRI techniques based on 3D acquisition sequences $[90,91]$ are the key components in the study of brain atrophy. DWI is also important in these models because this technique may show lesion formation even earlier than Gd contrast imaging [92]. Through the use of DTI methods, tract integrity is also studied [93]. Voxel-based MRS or chemical shift imaging studies are also used, mainly to assess axonal integrity and membrane turnover [91, 94].

Optic neuritis (ON) is an inflammatory demyelinating syndrome that may be seen as a standalone disease or as a typical component of MS and neuromyelitis optica. Due to the uniformity of the optic nerve fibers, ON models represent an obvious subject for DTI studies (FIG. 7) [95]. One research group demonstrated that in a mouse model of EAE-associated ON, autoimmune axonal injury correlated with a decrease in axial diffusivity, whereas demyelination correlated with changes in radial diffusivity, as measured by DWI [96]. This noninvasive method provides a means to test the efficacy of potential therapeutic agents.

\section{Neurodegenerative disease models}

In the study of neurodegenerative disease models, morphometric studies are used for atrophy measurements. Both global brain atrophy measurements as well as focal volume loss of brain structures are assessed using MRI [97-100]. One example is the recently reported cerebellar cortical atrophy in an EAE model [85]. 


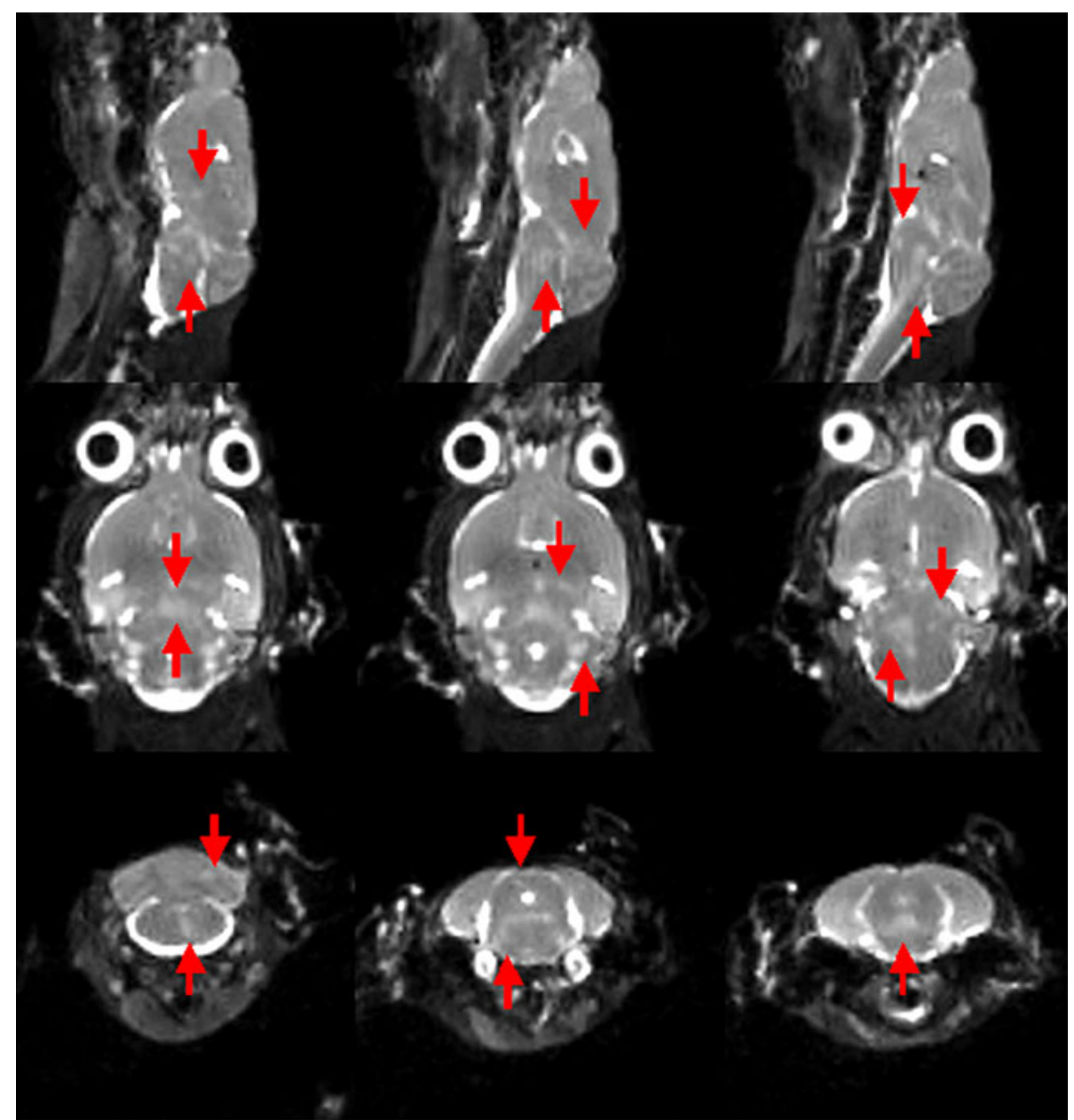

FIG. 6. Demyelinating lesions in interferon-y receptor knockout mice following TMEV infection. Note the high signal intensity areas (red arrows) in the brainstem and near the thalamus on these T2-weighted in vivo images. Reproduced with permission from I. Pirko et al. [150]. (High resolution version of this image is available in the electronic supplementary material.)

The pathology of Alzheimer's disease (AD) has been very difficult to study with MRI. However, through the use of novel contrast agents, one group has reported good success in imaging $\mathrm{AD}$ plaques ex vivo [101, 102]. More recently, even without contrast agents, plaque imaging in small rodent models has become possible both ex vivo [103] and in vivo (FIG. 8) [104-106]. Because amyloid plaque deposits contain iron, it was considered that $\mathrm{T}^{*}$ (GE) sequences would be best in visualizing the plaques, which in general are considered to be more sensitive to iron deposits than to spin echobased T2-weighted sequences. However in MS-related iron deposition of deep gray nuclei, T2-weighted-and not $\mathrm{T} 2 *$-weighted sequences - have been successful in capturing the phenomenon in both the human disease and one of its animal models [107, 108]. A recent comprehensive ex vivo study of a transgenic mouse model of $\mathrm{AD}$ provides an excellent comparative review of several MRI sequences, including T1W, T2W, T2* W, proton density, and SWI, and establishes the foundation for future in vivo studies [109].
Animal models for amyotrophic lateral sclerosis (ALS) are available, and MRI is becoming an attractive tool to study this disease. The most commonly studied animal model of ALS is a transgenic mouse that overexpresses a human G93A-SOD1 mutation [110]. Using this mouse model, two different groups have successfully used T2weighted MRI to visualize the neuronal degeneration of brain stem motor nuclei as well as to evaluate the disease progression [111-113]. More recently, DWI, specifically ADC studies have been suggested as an additional marker for the time-course evaluation of disease progression in ALS mice [114]. Another group used a model in which a cycad toxin introduced via the diet causes a neurodegeneration which resembles a human ALSParkinsonism dementia complex [115]. This group demonstrated that volumetric MR microscopy is a sensitive tool for detecting early neurodegeneration, and the result correlated well with histopathology findings and behavioral deficits.

Iron deposition as a component in the pathology of neurodegenerative diseases is also studied by MRI. 

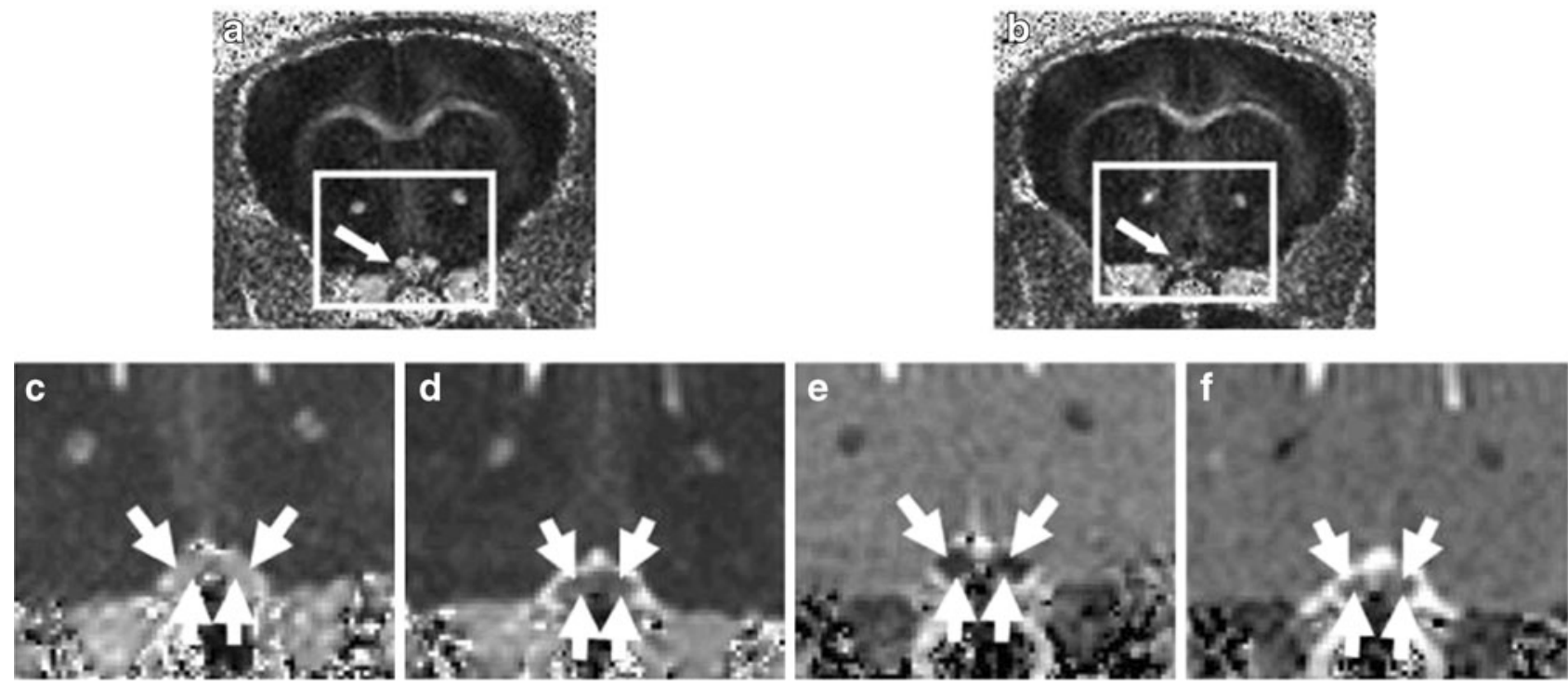

FIG. 7. Optic nerves (indicated by arrows) from the experimental autoimmune encephalomyelitis (EAE)-affected mouse appear hypointense $(B)$ in relative anisotropy (RA) maps compared with the control (A). Decreased axial diffusivity (D) and increased radial diffusivity (F) in optic nerves from EAE-affected mice were observed in the expanded views of axial $(C$ and $D)$ and radial diffusivity $(E$ and $F)$ corresponding to the rectangles in (A) and (B). Reproduced with permission from Xu et al. [95]. (High resolution version of this image is available in the electronic supplementary material.)

Changes suggestive of iron deposition are also seen in certain MS models, as recently reported by our team of investigators (FIG. 9) [85]. Since iron is known to cause susceptibility-related artifacts and high field strength imaging is more prone to these artifacts (see above), small animal MRI is very suitable to study this phenomenon [99].

\section{Stroke models}

Experimental stroke models in small rodents are frequently studied with MRI methods. These generally require classic MR imaging modalities, including T1, T2, and proton density imaging. Newer techniques include diffusion and perfusion imaging and MRS for determining certain metabolites [116, 117]. Many groups have used experimental middle cerebral artery ligation combined with hypoxia in rats or mice as models for human stroke (FIG. 10) [118, 119]. DWI sequences are especially sensitive to early ischemia, and many studies have utilized this resource in animal imaging, along with perfusion-weighted imaging, which is capable of visualizing the penumbra - the potentially salvageable area at risk [117, 120, 121]. Most recently, a novel mouse model of transient ischemic attack has been developed, as confirmed by DWI and T2-weighted MRI [122].

When DWI is performed using a fast imaging sequence like echo-planar imaging, the temporal resolution of scanning can be as low as every 20-30 s/entire brain scan, allowing close monitoring of stroke development. MRS studies have been conducted with the aim of looking at the lactate peak, which becomes prominent when anaerobic glycolysis predominates $[116,117,123]$. Another important aspect is the $\mathrm{N}$-acetyl-aspartate peak that may show a decrease in completed strokes, but may remain normal if the animals still can recover from the ischemic event [124]. Magnetic resonance angiography [125] and perfusion-weighted imaging [57] have been performed and evaluated in several stroke models. These studies accurately characterize the cerebral blood flow and blood volume during ischemia.

Experimental intracerebral hemorrhages in animal models have been developed and only recently studied by MRI. In a warfarin-induced intracerebral hemorrhage model, T2* MRI was shown to almost perfectly correlate with the hematoma size observed from cryo-sections [126]. Another group used direct infusion of autologous blood in a rat striatum as a model and demonstrated that MRI also correlated with histopathological features [127]. Taken overall, these results suggest that MRI is very useful as a tool to evaluate functional outcomes after treatments as well as to elucidate their mechanism of action.

Traumatic injury models of the brain and spinal cord

Several models of traumatic brain injury have been developed in experimental animals. These range from diffuse injuries to controlled cortical impacts, chemical insults, and nonimpact models. MRI allows monitoring of the damaged tissue, also the tissue at risk [12, 128, 129]. For this purpose, DWI/DTI/magnetization transfer (MT) techniques are often used, similarly to the stroke studies described above. One group has provided 


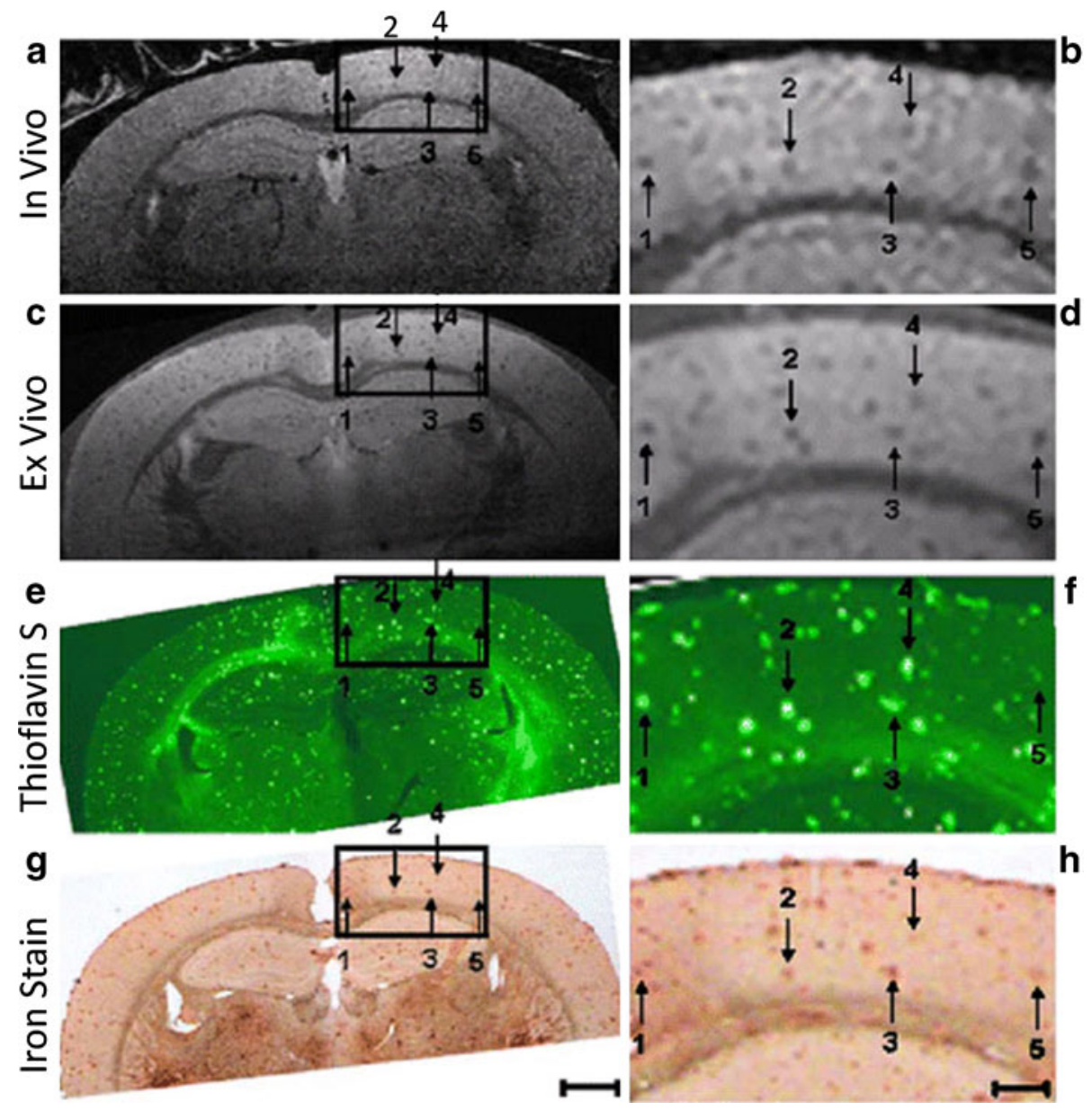

FIG. 8. 12-month-old Alzheimer's disease (AD) mouse. In vivo (a, b) and ex vivo (c, d) $\mathrm{T}_{2} \mathrm{SE}$-weighted MR images, thioflavin-S-stained $(e, f)$ and iron-stained $(g, h)$ histological brain sections have been precisely spatially registered over a circumscribed area of the cortex, indicated by the box. The boxes in the right column (scale bar, $100 \mu \mathrm{m}$ ) represent $3 \times$ magnified portions of the adjacent parent image in the left column (scale bar, $1.0 \mathrm{~mm}$ ). The numbered arrows indicate individual plaques visualized in each of the four different image types that matched with the linked-cursor system. Reproduced with permission from C.R. Jack [106]. (High resolution version of this image is available in the electronic supplementary material.)

evidence that DTI signal abnormalities correlate with electron microscopic and histological features of pericontusional injury. Based on these findings, these researchers propose DTI as an important tool to validate these injuries and predict approximate time since trauma [130, 131] (FIG. 11). Another group utilized a rat model and demonstrated that DWI was useful for the in vivo examination of brain edema following traumatic brain injury, with or without secondary hypoxia [132]. MRS may also be utilized for the study of tissue injury in the CNS [133, 134].

Spinal cord injury is most commonly studied in rats. Traditionally, spinal cord integrity and neural circuitry either under normal conditions or after injury are studied by using histology and immunohistochemistry [135137]. During the last decade several MRI techniques have been utilized for in vivo research in spinal cord injury models. Diffusion anisotropy MRI has been suggested as an approach for quantitative assessment of secondary degeneration and recovery after spinal cord injury in rats
[138]. Moreover, a good correlation between functional MRI activation in the rat spinal cord with neuronal activity determined by immunohistochemistry has been reported [139]. In addition, MEMRI may be a sensitive in vivo method for assessing neuronal functionality after spinal cord injury and eventual treatment outcomes. The main limitation in using MEMRI in vivo is the dose-dependent neurotoxicity of manganese [140].

\section{Brain tumor models}

Animal models of brain tumors are also frequently studied by MRI and MRS (FIG. 12) [141-143]. The basic T1- and T2-weighted techniques may not always allow an obvious delineation between healthy and tumor infiltrate. Thus, advanced MRI methods and cell-labeling techniques are needed for the identification of transplanted tumor cells and growth monitoring. A combination of several MRI methods may enable visualization of human neural stem cells targeting the brain tumor [144]. 

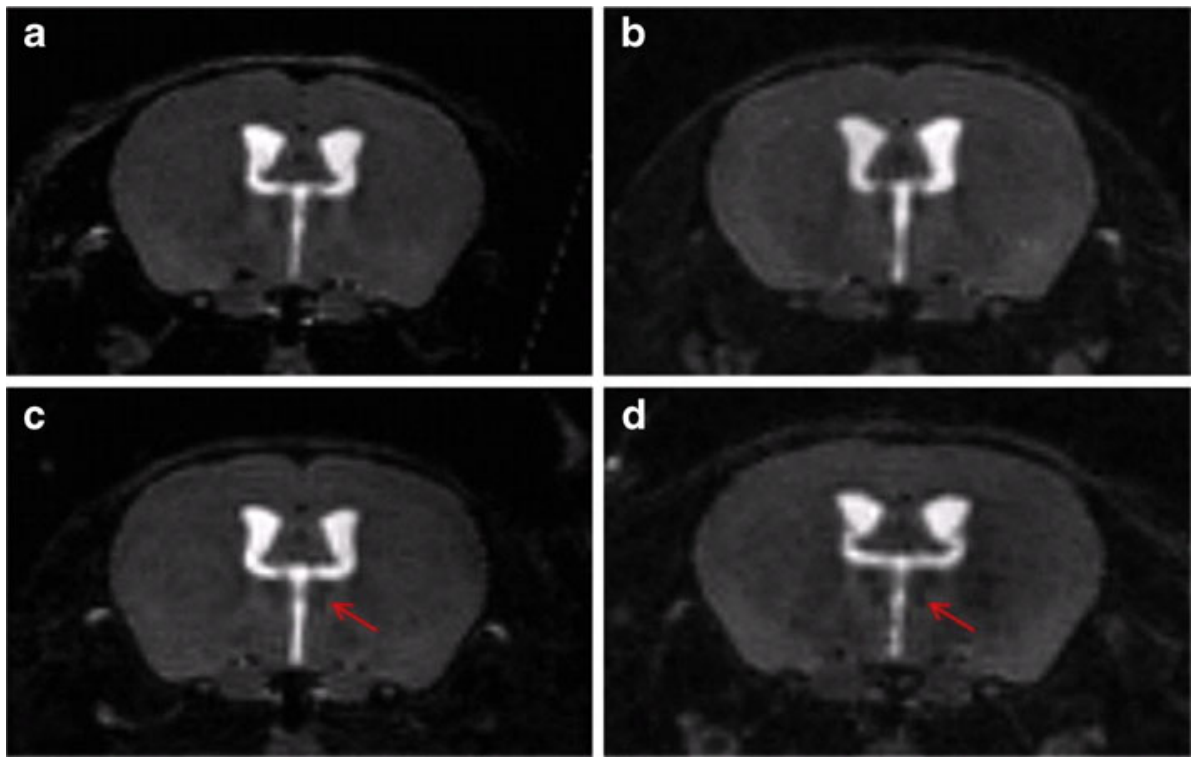

FIG. 9. Example of progressive thalamic T2 hypointensity in a virally induced multiple sclerosis (MS) model at 1 (A), 4 (B), 6 (C), and 12 (D) months postdisease induction. A-D represent coronal slices extracted from the original 3D datasets. Note the hypointensity of the mediodorsal thalamic nucleus and the increasing hypointensity at the later time points (arrows). (High resolution version of this image is available in the electronic supplementary material.)

The use of intravenous contrast materials shows a blood-brain barrier breakdown in certain tumor models. MRS studies (proton and phosphorous) are also used to study biochemical differences between cancerous and normal tissue in vivo. Diffusion and perfusion studies together with blood flow and BOLD studies may provide useful information because tumor cells generally show increased metabolism [145, 146]. A recent study described a new radiation necrosis mouse model [147]. This important study provided milestones in the development of MRI tools to distinguish radiation changes from tumor recurrence. Chemical shift imaging is a multivoxel MRS method that may be particularly useful in studying the various brain diseases [90]. In addition, a novel method of heteronuclear imaging has emerged. Kato et al. $[148,149]$ utilized ${ }^{1} \mathrm{H} /{ }^{13} \mathrm{C}$ magnetic resonance spectroscopic imaging to noninvasively analyze the delivery pattern and intratumoral distribution of the ${ }^{13} \mathrm{C}$-labeled anti-cancer drug temozolomide, which is commonly used in treatment of several brain tumors.

\section{CONCLUSIONS}

Over the last several years, microscopic resolution in vivo MRI has become a popular and versatile tool in the

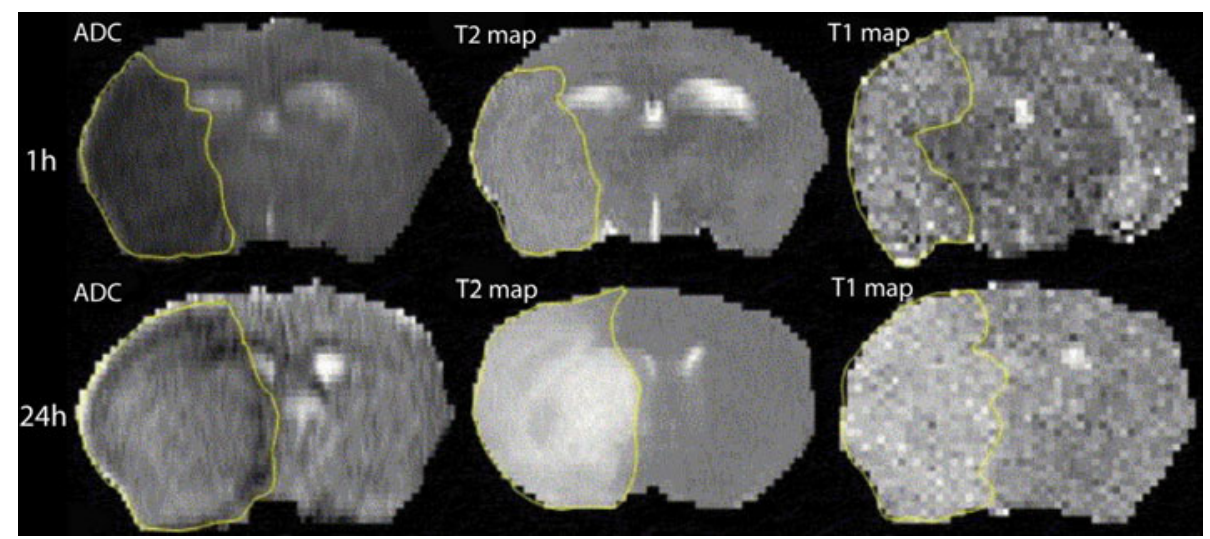

FIG. 10. ADC, T2, and T1 maps show the severity and growth of the lesion in the mouse stroke model induced by a transient middle cerebral artery occlusion (reproduced with permission from P.A. Barber et al. [119]). Images on the top row were obtained 50-60 min after reperfusion, and images on the bottom row are of similar slices $24 \mathrm{~h}$ later. (High resolution version of this image is available in the electronic supplementary material.) 

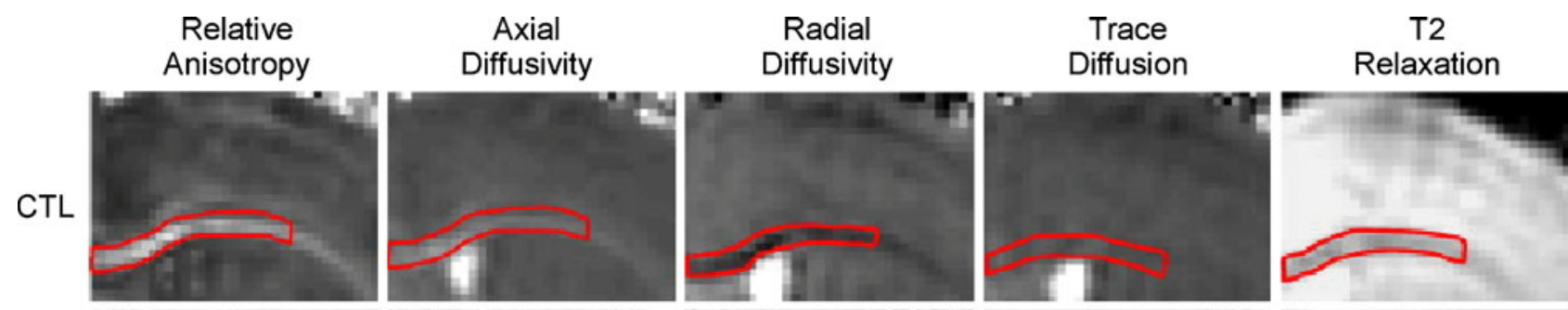

TBI
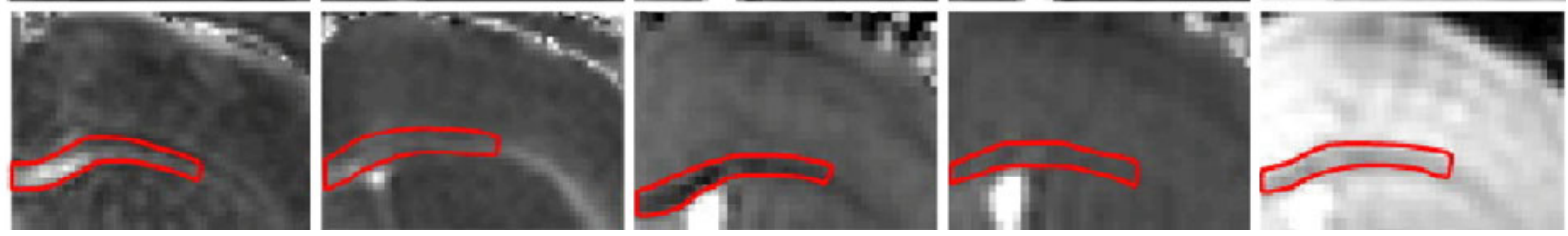

FIG. 11. Diffusion tensor imaging of normal mouse brain (top row) and mouse brain $24 \mathrm{~h}$ following TBI (bottom row) (Reproduced from C.L. Mac Donald et al. [131]. Relative anisotropy and axial diffusivity show a gradient of signal changes within the red outlined area on post-TBI as compared to normal brain images. Other images showing radial diffusivity, trace diffusion and T2-weighted images are similar in the normal and injured brain. $\mathrm{CTL}=$ Control, $\mathrm{TBI}=$ Traumatic brain injury. (High resolution version of this image is available in the electronic supplementary material.)

study of CNS diseases. MR image resolution of tens of microns in all three dimensions can now be achieved for in vivo studies, although for most practical applications, an isometric resolution of approximately $100 \mu \mathrm{m}$ is sufficient. Because of the obstacles encountered with physiological microscopic movements of tissues due to circulation, breathing, and fluid flow, significantly higher resolutions are probably unrealistic for in vivo applications; the numerous inherent artifacts related to high field strength imaging have also to be kept in mind. New developments from the fields of neutron magnetic reso- nance and clinical MRI research will find their way to small animal experimental MRI research. Since a growing number of human CNS diseases have MRI-based diagnostic criteria, translational MRI research utilizing rodent models allows insight into important substrates of tissue dysfunction related to these clinically relevant MRI findings. The increased versatility that microscopic resolution MRI provides will result in enhanced understanding of critically important biological processes and in the development of new diagnostic and treatment approaches in a variety of human CNS diseases.
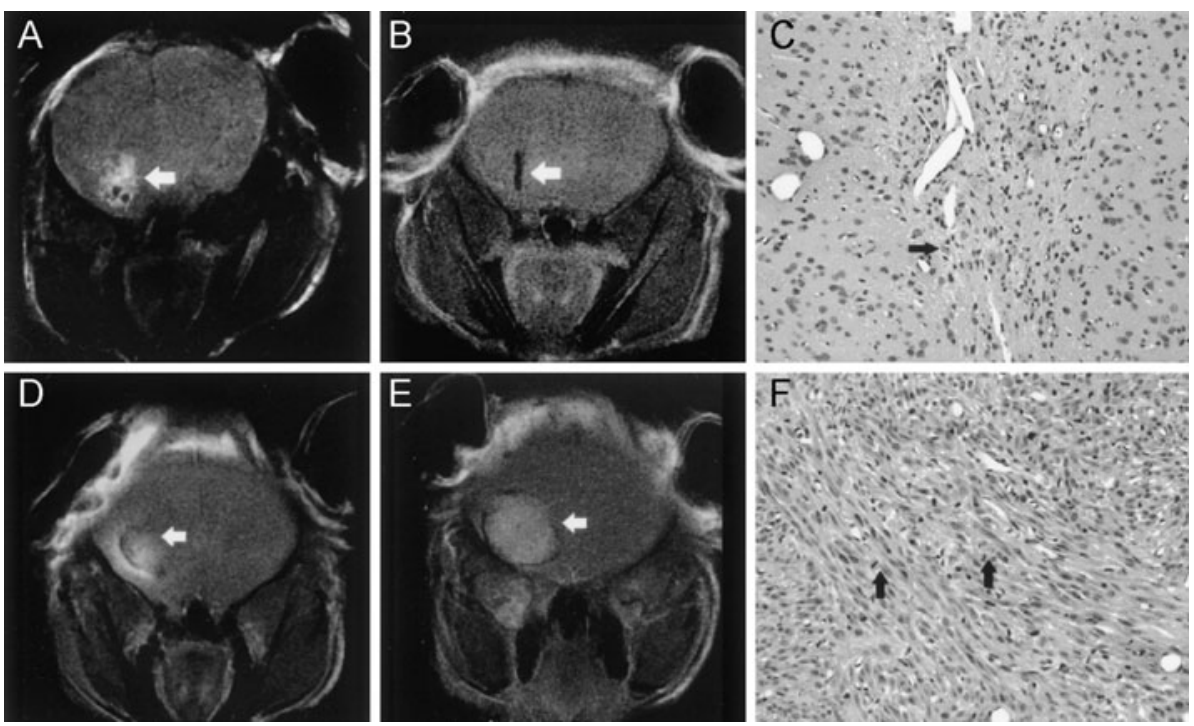

FIG. 12. MR imaging in a mouse model of a brain tumor showing a different outcome after two treatments (Reproduced with permission from L.K. Phuong et al. [143]. Panels (A) and (D) are brain MRI scans before the treatment, whereas (B) and (E) are the MRI scans 18 days after the different treatments. (B) Note the complete regression of a tumor treated with measles virus genetically engineered to produce carcinoembryonic antigen (MV-CEA) with a visible needle trace. (C) A stained (hematoxylin/eosin; H\&E) brain section from the same mouse shows no residual tumor cells except for the glial scar and macrophages (arrows) (×200). (E) Mouse treated with UV-inactivated MV-CEA shows a profound tumor growth. (F) H\&E stain from the same mouse's brain shows a hypercellular U87 tumor with frequent mitotic figures (arrows) (×200). (High resolution version of this image is available in the electronic supplementary material.) 


\section{REFERENCES}

1. Hansen G, Crooks LE, Davis P, et al. In vivo imaging of the rat anatomy with nuclear magnetic resonance. Radiology 1980;136:695-700.

2. Andjus RK, Dzakula Z, Markley JL, Macura S. Brain energetics and tolerance to anoxia in deep hypothermia. Ann N Y Acad Sci 2005; 1048:10-35.

3. Raghunand $\mathrm{N}$. Tissue $\mathrm{pH}$ measurement by magnetic resonance spectroscopy and imaging. Methods Mol Med 2006;124:347364.

4. Robb RA. 3-D visualization in biomedical applications. Annu Rev Biomed Eng 1999;1:377-399.

5. Robb RA. The virtualization of medicine: a decade of pitfalls and progress. Stud Health Technol Inform 2002;85:1-7.

6. Turner R, Howseman A, Rees GE, Josephs O, Friston K. Functional magnetic resonance imaging of the human brain: data acquisition and analysis. Exp Brain Res 1998;123:5-12.

7. Ge Y, Grossman RI, Udupa JK, et al. Brain atrophy in relapsingremitting multiple sclerosis: fractional volumetric analysis of gray matter and white matter. Radiology 2001;220:606-610.

8. http://rsb.info.nih.gov/nih-image/Default.html Website accessed 12/ $15 / 2010$.

9. Suidan GL, Pirko I, Johnson AJ. A potential role for CD8+ T-cells as regulators of CNS vascular permeability. Neurol Res 2006;28:250-255.

10. Lukasik VM, Gillies RJ. Animal anaesthesia for in vivo magnetic resonance. NMR Biomed 2003;16:459-467.

11. Kannurpatti SS, Biswal BB. Effect of anesthesia on CBF, MAP and fMRI-BOLD signal in response to apnea. Brain Res 2004;1011:141-147.

12. Fricke ST, Vink R, Chiodo C, et al. Consistent and reproducible slice selection in rodent brain using a novel stereotaxic device for MRI. J Neurosci Methods 2004;136:99-102.

13. Bernstein MA, Huston J, 3rd, Ward HA. Imaging artifacts at 3.0T. J Magn Reson Imaging 2006;24:735-746.

14. Yang QX, Williams GD, Demeure RJ, Mosher TJ, Smith MB. Removal of local field gradient artifacts in $\mathrm{T} 2 *$-weighted images at high fields by gradient-echo slice excitation profile imaging. Magn Reson Med 1998;39:402-409.

15. Yang QX, Demeure RJ, Dardzinski BJ, Arnold BW, Smith MB. Multiple echo frequency-domain image contrast: improved signalto-noise ratio and T2 (T2*) weighting. Magn Reson Med 1999;41:423-428.

16. Frahm J, Merboldt KD, Hanicke W. Direct FLASH MR imaging of magnetic field inhomogeneities by gradient compensation. Magn Reson Med 1988;6:474-480.

17. Ordidge RJ, Gorell JM, Deniau JC, Knight RA, Helpern JA. Assessment of relative brain iron concentrations using T2weighted and T2*-weighted MRI at 3 Tesla. Magn Reson Med 1994;32:335-341.

18. Hennig J, Friedburg H. Clinical applications and methodological developments of the RARE technique. Magn Reson Imaging 1988;6:391-395.

19. Haacke EM. Susceptibility weighted imaging (SWI). Z Med Phys 2006;16:237.

20. Haacke EM, Mittal S, Wu Z, Neelavalli J, Cheng YC. Susceptibility-weighted imaging: technical aspects and clinical applications, part 1. AJNR Am J Neuroradiol 2009;30:19-30.

21. Haacke EM, Xu Y, Cheng YC, Reichenbach JR. Susceptibility weighted imaging (SWI). Magn Reson Med 2004;52:612-618.

22. Haacke EM, Cheng NY, House MJ, et al. Imaging iron stores in the brain using magnetic resonance imaging. Magn Reson Imaging 2005;23:1-25.

23. Lee BC, Vo KD, Kido DK, et al. MR high-resolution blood oxygenation level-dependent venography of occult (low-flow) vascular lesions. AJNR Am J Neuroradiol 1999;20:1239-1242.

24. Lin W, Mukherjee P, An H, et al. Improving high-resolution MR bold venographic imaging using a T1 reducing contrast agent. J Magn Reson Imaging 1999;10:118-123.

25. Reichenbach JR, Barth M, Haacke EM, et al. High-resolution MR venography at 3.0 Tesla. J Comput Assist Tomogr 2000;24:949957.
26. Reichenbach JR, Jonetz-Mentzel L, Fitzek C, et al. High-resolution blood oxygen-level dependent MR venography (HRBV): a new technique. Neuroradiology 2001;43:364-369.

27. Essig M, Reichenbach JR, Schad LR, et al. High-resolution MR venography of cerebral arteriovenous malformations. Magn Reson Imaging 1999;17:1417-1425.

28. Essig M, Reichenbach JR, Schad L, Debus J, Kaiser WA. [High resolution MR-venography of cerebral arteriovenous malformations]. Radiologe 2001;41:288-295.

29. Tong KA, Ashwal S, Holshouser BA, et al. Hemorrhagic shearing lesions in children and adolescents with posttraumatic diffuse axonal injury: improved detection and initial results. Radiology 2003;227:332-339.

30. Barth M, Nobauer-Huhmann IM, Reichenbach JR, et al. Highresolution three-dimensional contrast-enhanced blood oxygenation level-dependent magnetic resonance venography of brain tumors at 3 Tesla: first clinical experience and comparison with 1.5 Tesla. Invest Radiol 2003;38:409-414.

31. Hamans BC, Barth M, Leenders WP, Heerschap A. Contrast enhanced susceptibility weighted imaging (CE-SWI) of the mouse brain using ultrasmall superparamagnetic ironoxide particles (USPIO). Z Med Phys 2006;16:269-274.

32. Tan IL, van Schijndel RA, Pouwels PJ, et al. MR venography of multiple sclerosis. AJNR Am J Neuroradiol 2000;21:1039-1042.

33. Jacobs RE, Papan C, Ruffins S, Tyszka JM, Fraser SE. MRI: volumetric imaging for vital imaging and atlas construction. Nat Rev Mol Cell Biol 2003; (Suppl):SS10-16.

34. Dhenain M, Ruffins SW, Jacobs RE. Three-dimensional digital mouse atlas using high-resolution MRI. Dev Biol 2001;232:458-470.

35. MacKenzie-Graham A, Lee EF, Dinov ID, et al. A multimodal, multidimensional atlas of the $\mathrm{C} 57 \mathrm{BL} / 6 \mathrm{~J}$ mouse brain. J Anat 2004;204:93-102.

36. Kovacevic N, Henderson JT, Chan E, et al. A three-dimensional MRI atlas of the mouse brain with estimates of the average and variability. Cereb Cortex 2004;15:639-645.

37. Jacobs RE, Ahrens ET, Dickinson ME, Laidlaw D. Towards a microMRI atlas of mouse development. Comput Med Imaging Graph 1999;23:15-24.

38. Dalton CM, Brex PA, Jenkins R, et al. Progressive ventricular enlargement in patients with clinically isolated syndromes is associated with the early development of multiple sclerosis. J Neurol Neurosurg Psychiatry 2002;73:141-147.

39. http://mouseatlas.caltech.edu Site accessed on 12/15/2010

40. Lin YJ, Koretsky AP. Manganese ion enhances T1-weighted MRI during brain activation: an approach to direct imaging of brain function. Magn Reson Med 1997;38:378-388.

41. Drapeau P, Nachshen DA. Manganese fluxes and manganesedependent neurotransmitter release in presynaptic nerve endings isolated from rat brain. J Physiol 1984;348:493-510.

42. Pautler RG, Mongeau R, Jacobs RE. In vivo trans-synaptic tract tracing from the murine striatum and amygdala utilizing manganese enhanced MRI (MEMRI). Magn Reson Med 2003;50:33-39.

43. Pautler RG, Koretsky AP. Tracing odor-induced activation in the olfactory bulbs of mice using manganese-enhanced magnetic resonance imaging. Neuroimage 2002;16:441-448.

44. Hu TC, Pautler RG, MacGowan GA, Koretsky AP. Manganeseenhanced MRI of mouse heart during changes in inotropy. Magn Reson Med 2001;46:884-890.

45. Pautler RG, Silva AC, Koretsky AP. In vivo neuronal tract tracing using manganese-enhanced magnetic resonance imaging. Magn Reson Med 1998;40:740-748.

46. Bilgen M, Dancause N, Al-Hafez B, He YY, Malone TM Manganese-enhanced MRI of rat spinal cord injury. Magn Reson Imaging 2005;23:829-832.

47. Bilgen M. Imaging corticospinal tract connectivity in injured rat spinal cord using manganese-enhanced MRI. BMC Med Imaging 2006;6:15

48. Stieltjes B, Klussmann S, Bock M, et al. Manganese-enhanced magnetic resonance imaging for in vivo assessment of damage and functional improvement following spinal cord injury in mice. Magn Reson Med 2006;55:1124-1131.

49. Yang J, Wu EX. Manganese-enhanced MRI detected the gray matter lesions in the late phase of mild hypoxic-ischemic injury 
in neonatal rat. Conf Proc IEEE Eng Med Biol Soc 2007;2007:51-54.

50. Bock C, Schmitz B, Kerskens CM, et al. Functional MRI of somatosensory activation in rat: effect of hypercapnic upregulation on perfusion- and BOLD-imaging. Magn Reson Med 1998;39:457-461.

51. Mandeville JB, Marota JJ, Kosofsky BE, et al. Dynamic functional imaging of relative cerebral blood volume during rat forepaw stimulation. Magn Reson Med 1998;39:615-624.

52. Malisza KL, Stroman PW. Functional imaging of the rat cervical spinal cord. J Magn Reson Imaging 2002;16:553-558.

53. Malisza KL, Stroman PW, Turner A, et al. Functional MRI of the rat lumbar spinal cord involving painful stimulation and the effect of peripheral joint mobilization. J Magn Reson Imaging 2003;18:152-159.

54. Brinker G, Bock C, Busch E, et al. Simultaneous recording of evoked potentials and $\mathrm{T} 2 *$-weighted MR images during somatosensory stimulation of rat. Magn Reson Med 1999;41:469-473.

55. Hsu EW, Hedlund LW, MacFall JR. Functional MRI of the rat somatosensory cortex: effects of hyperventilation. Magn Reson Med 1998;40:421-426.

56. Mandeville JB, Jenkins BG, Kosofsky BE, et al. Regional sensitivity and coupling of BOLD and CBV changes during stimulation of rat brain. Magn Reson Med 2001;45:443-447.

57. Wu EX, Wong KK, Andrassy M, Tang H. High-resolution in vivo CBV mapping with MRI in wild-type mice. Magn Reson Med 2003;49:765-770.

58. Lawrence J, Stroman PW, Malisza KL. Functional MRI of the cervical spinal cord during noxious and innocuous thermal stimulation in the alpha-chloralose- and halothane-anesthetized rat. Magn Reson Imaging 2008;26:1-10.

59. Majcher K, Tomanek B, Jasinski A, et al. Simultaneous functional magnetic resonance imaging in the rat spinal cord and brain. Exp Neurol 2006;197:458-464.

60. Pirko I, Ciric B, Gamez J, et al. A human antibody that promotes remyelination enters the CNS and decreases lesion load as detected by T2-weighted spinal cord MRI in a virus-induced murine model of MS. FASEB J 2004;18:1577-1579.

61. Pirko I, Johnson A, Ciric B, et al. In vivo magnetic resonance imaging of immune cells in the central nervous system with superparamagnetic antibodies. FASEB J 2004;18:179-182.

62. Pirko I, Ciric B, Johnson AJ, et al. Magnetic resonance imaging of immune cells in inflammation of central nervous system. Croat Med J 2003;44:463-468.

63. Bulte JW, Kraitchman DL. Iron oxide MR contrast agents for molecular and cellular imaging. NMR Biomed 2004;17:484-499.

64. Bulte JW, Arbab AS, Douglas T, Frank JA. Preparation of magnetically labeled cells for cell tracking by magnetic resonance imaging. Methods Enzymol 2004;386:275-299.

65. Bulte JW, Ben-Hur T, Miller BR, et al. MR microscopy of magnetically labeled neurospheres transplanted into the Lewis EAE rat brain. Magn Reson Med 2003;50:201-205.

66. Anderson SA, Shukaliak-Quandt J, Jordan EK, et al. Magnetic resonance imaging of labeled T-cells in a mouse model of multiple sclerosis. Ann Neurol 2004;55:654-659.

67. Weissleder R, Elizondo G, Wittenberg J, et al. Ultrasmall superparamagnetic iron oxide: characterization of a new class of contrast agents for MR imaging. Radiology 1990;175:489-493.

68. Shapiro EM, Skrtic S, Koretsky AP. Sizing it up: cellular MRI using micron-sized iron oxide particles. Magn Reson Med 2005;53:329-338.

69. Stark DD, Weissleder R, Elizondo G, et al. Superparamagnetic iron oxide: clinical application as a contrast agent for MR imaging of the liver. Radiology 1988;168:297-301.

70. Weissleder R, Hahn PF, Stark DD, et al. Superparamagnetic iron oxide: enhanced detection of focal splenic tumors with MR imaging. Radiology 1988;169:399-403.

71. Robinson KM, Njus JM, Phillips DA, et al. MR imaging of inflammation during myelin-specific $\mathrm{T}$ cell-mediated autoimmune attack in the EAE mouse spinal cord. Mol Imaging Biol 2010;12:240-249.

72. Ladewig G, Jestaedt L, Misselwitz B, et al. Spatial diversity of blood-brain barrier alteration and macrophage invasion in exper- imental autoimmune encephalomyelitis: a comparative MRI study. Exp Neurol 2009;220:207-211.

73. Xu S, Jordan EK, Brocke S, et al. Study of relapsing remitting experimental allergic encephalomyelitis SJL mouse model using MION-46L enhanced in vivo MRI: early histopathological correlation. J Neurosci Res 1998;52:549-558.

74. Dousset V, Ballarino L, Delalande C, et al. Comparison of ultrasmall particles of iron oxide (USPIO)-enhanced T2-weighted, conventional T2-weighted, and gadolinium-enhanced T1-weighted MR images in rats with experimental autoimmune encephalomyelitis. AJNR Am J Neuroradiol 1999;20:223-227.

75. Rausch M, Hiestand P, Baumann D, Cannet C, Rudin M. MRIbased monitoring of inflammation and tissue damage in acute and chronic relapsing EAE. Magn Reson Med 2003;50:309314.

76. Pirko I, Nolan TK, Holland SK, Johnson AJ. Multiple sclerosis: pathogenesis and MR imaging features of T1 hypointensities in a [corrected] murine model. Radiology 2008;246:790-795.

77. OudeEngberink RD, van der Pol SM, Dopp EA, de Vries HE, Blezer EL. Comparison of SPIO and USPIO for in vitro labeling of human monocytes: MR detection and cell function. Radiology 2007;243:467-474

78. Thorek DL, Tsourkas A. Size, charge and concentration dependent uptake of iron oxide particles by non-phagocytic cells. Biomaterials 2008;29:3583-3590.

79. Metz S, Bonaterra G, Rudelius M, et al. Capacity of human monocytes to phagocytose approved iron oxide MR contrast agents in vitro. Eur Radiol 2004;14:1851-1858.

80. McAteer MA, Sibson NR, von Zur Muhlen C, et al. In vivo magnetic resonance imaging of acute brain inflammation using microparticles of iron oxide. Nat Med 2007;13:1253-1258.

81. Querol M, Bogdanov A, Jr. Amplification strategies in MR imaging: activation and accumulation of sensing contrast agents (SCAs). J Magn Reson Imaging 2006;24:971-982.

82. Chen JW, Querol Sans M, Bogdanov A, Jr., Weissleder R. Imaging of myeloperoxidase in mice by using novel amplifiable paramagnetic substrates. Radiology 2006;240:473-481.

83. Kim JH, Budde MD, Liang HF, et al. Detecting axon damage in spinal cord from a mouse model of multiple sclerosis. Neurobiol Dis 2006;21:626-632.

84. MacKenzie-Graham A, Tiwari-Woodruff SK, Sharma G, et al. Purkinje cell loss in experimental autoimmune encephalomyelitis. Neuroimage 2009;48:637-651.

85. Pirko I, Johnson AJ, Lohrey AK, Chen Y, Ying J. Deep gray matter T2 hypointensity correlates with disability in a murine model of MS. J Neurol Sci 2009;282:34-38.

86. Pirko I, Suidan GL, Rodriguez M, Johnson AJ. Acute hemorrhagic demyelination in a murine model of multiple sclerosis. J Neuroinflammation 2008;5:31.

87. Wu QZ, Yang Q, Cate HS, et al. MRI identification of the rostralcaudal pattern of pathology within the corpus callosum in the cuprizone mouse model. J Magn Reson Imaging 2008;27:446-453.

88. Zaaraoui W, Deloire M, Merle M, et al. Monitoring demyelination and remyelination by magnetization transfer imaging in the mouse brain at 94T. Magma 2008;21:357-362.

89. Sun SW, Liang HF, Trinkaus K, et al. Noninvasive detection of cuprizone induced axonal damage and demyelination in the mouse corpus callosum. Magn Reson Med 2006;55:302-308.

90. Pirko I, Gamez J, Johnson AJ, Macura SI, Rodriguez M. Dynamics of MRI lesion development in an animal model of viral-induced acute progressive CNS demyelination. NeuroImage 2004;21:576-582.

91. Pirko I, Johnson A, Gamez J, Macura SI, Rodriguez M. Disappearing "T1 black holes" in an animal model of multiple sclerosis. Front Biosci 2004;9:1222-1227.

92. Heide AC, Richards TL, Alvord EC, Jr., Peterson J, Rose LM. Diffusion imaging of experimental allergic encephalomyelitis. Magn Reson Med 1993;29:478-484.

93. Ahrens ET, Laidlaw DH, Readhead C, et al. MR microscopy of transgenic mice that spontaneously acquire experimental allergic encephalomyelitis. Magn Reson Med 1998;40:119-132.

94. Schwarcz A, Natt O, Watanabe T, et al. Localized proton MRS of cerebral metabolite profiles in different mouse strains. Magn Reson Med 2003;49:822-827. 
95. Xu J, Sun SW, Naismith RT, et al. Assessing optic nerve pathology with diffusion MRI: from mouse to human. NMR Biomed 2008;21:928-940.

96. Wu Q, Butzkueven H, Gresle M, et al. MR diffusion changes correlate with ultra-structurally defined axonal degeneration in murine optic nerve. Neuroimage 2007;37:1138-1147.

97. Lee WT, Chang C. Magnetic resonance imaging and spectroscopy in assessing 3-nitropropionic acid-induced brain lesions: an animal model of Huntington's disease. Prog Neurobiol 2004;72:87-110.

98. Choi IY, Lee SP, Guilfoyle DN, Helpern JA. In vivo NMR studies of neurodegenerative diseases in transgenic and rodent models. Neurochem Res 2003;28:987-1001.

99. Gilissen EP, Ghosh P, Jacobs RE, Allman JM. Topographical localization of iron in brains of the aged fat-tailed dwarf lemur (Cheirogaleus medius) and gray lesser mouse lemur (Microcebus murinus). Am J Primatol 1998;45:291-299.

100. McDaniel B, Sheng H, Warner DS, Hedlund LW, Benveniste H. Tracking brain volume changes in C57BL/6J and ApoE-deficient mice in a model of neurodegeneration: a 5-week longitudinal micro-MRI study. NeuroImage 2001;14:1244-1255.

101. Poduslo JF, Wengenack TM, Curran GL, et al. Molecular targeting of Alzheimer's amyloid plaques for contrast-enhanced magnetic resonance imaging. Neurobiol Dis 2002;11:315-329.

102. Poduslo JF, Curran GL, Peterson JA, et al. Design and chemical synthesis of a magnetic resonance contrast agent with enhanced in vitro binding, high blood-brain barrier permeability, and in vivo targeting to Alzheimer's disease amyloid plaques. Biochemistry 2004;43:6064-6075.

103. Zhang J, Yarowsky P, Gordon MN, et al. Detection of amyloid plaques in mouse models of Alzheimer's disease by magnetic resonance imaging. Magn Reson Med 2004;51:452-457.

104. Dedeoglu A, Choi JK, Cormier K, Kowall NW, Jenkins BG. Magnetic resonance spectroscopic analysis of Alzheimer's disease mouse brain that express mutant human APP shows altered neurochemical profile. Brain Res 2004;1012:60-65.

105. Jack CR, Jr., Garwood M, Wengenack TM, et al. In vivo visualization of Alzheimer's amyloid plaques by magnetic resonance imaging in transgenic mice without a contrast agent. Magn Reson Med 2004;52:1263-1271.

106. Jack CR, Jr., Marjanska M, Wengenack TM, et al. Magnetic resonance imaging of Alzheimer's pathology in the brains of living transgenic mice: a new tool in Alzheimer's disease research. Neuroscientist 2007;13:38-48.

107. Bakshi R, Dmochowski J, Shaikh ZA, Jacobs L. Gray matter T2 hypointensity is related to plaques and atrophy in the brains of multiple sclerosis patients. J Neurol Sci 2001;185:19-26.

108. Pirko I, Johnson AJ, Lohrey AK, Chen Y, Ying J. Deep gray matter T2 hypointensity correlates with disability in a murine model of MS. J Neurol Sci 2009;282:34-38.

109. Chamberlain R, Reyes D, Curran GL, et al. Comparison of amyloid plaque contrast generated by $\mathrm{T} 2$-weighted, $\mathrm{T} 2 *$-weighted, and susceptibility-weighted imaging methods in transgenic mouse models of Alzheimer's disease. Magn Reson Med 2009;61:1158 1164.

110. Gurney ME, Pu H, Chiu AY, et al. Motor neuron degeneration in mice that express a human $\mathrm{Cu}, \mathrm{Zn}$ superoxide dismutase mutation. Science 1994;264:1772-1775.

111. Angenstein F, Niessen HG, Goldschmidt J, et al. Age-dependent changes in MRI of motor brain stem nuclei in a mouse model of ALS. Neuroreport 2004;15:2271-2274.

112. Zang DW, Yang Q, Wang HX, et al. Magnetic resonance imaging reveals neuronal degeneration in the brainstem of the superoxide dismutase 1 transgenic mouse model of amyotrophic lateral sclerosis. Eur J Neurosci 2004;20:1745-1751.

113. Bucher S, Braunstein KE, Niessen HG, et al. Vacuolization correlates with spin-spin relaxation time in motor brainstem nuclei and behavioural tests in the transgenic G93A-SOD1 mouse model of ALS. Eur J Neurosci 2007;26:1895-1901.

114. Niessen HG, Angenstein F, Sander K, et al. In vivo quantification of spinal and bulbar motor neuron degeneration in the G93A-SOD1 transgenic mouse model of ALS by T2 relaxation time and apparent diffusion coefficient. Exp Neurol 2006;201:293-300.
115. Wilson JM, Petrik MS, Grant SC, et al. Quantitative measurement of neurodegeneration in an ALS-PDC model using MR microscopy. Neuroimage 2004;23:336-343.

116. Hesselbarth D, Franke C, Hata R, Brinker G, Hoehn-Berlage M. High resolution MRI and MRS: a feasibility study for the investigation of focal cerebral ischemia in mice. NMR Biomed 1998;11:423-429.

117. Hoehn M, Nicolay K, Franke C, van der Sanden B. Application of magnetic resonance to animal models of cerebral ischemia. $\mathrm{J}$ Magn Reson Imaging 2001;14:491-509.

118. Hata R, Mies G, Wiessner C, et al. A reproducible model of middle cerebral artery occlusion in mice: hemodynamic, biochemical, and magnetic resonance imaging. J Cereb Blood Flow Metab 1998;18:367-375.

119. Barber PA, Hoyte L, Kirk D, et al. Early T1- and T2-weighted MRI signatures of transient and permanent middle cerebral artery occlusion in a murine stroke model studied at 9.4T. Neurosci Lett 2005;388:54-59.

120. Xue R, van Zijl PC, Crain BJ, Solaiyappan M, Mori S. In vivo three-dimensional reconstruction of rat brain axonal projections by diffusion tensor imaging. Magn Reson Med 1999;42:11231127.

121. Tatlisumak T, Strbian D, Abo Ramadan U, Li F. The role of diffusion- and perfusion-weighted magnetic resonance imaging in drug development for ischemic stroke: from laboratory to clinics. Curr Vasc Pharmacol 2004;2:343-355.

122. Pedrono E, Durukan A, Strbian D, et al. An optimized mouse model for transient ischemic attack. J Neuropathol Exp Neurol 2010;69:188-195.

123. Dreher W, Kuhn B, Gyngell ML, et al. Temporal and regional changes during focal ischemia in rat brain studied by proton spectroscopic imaging and quantitative diffusion NMR imaging. Magn Reson Med 1998;39:878-888.

124. Malisza KL, Kozlowski P, Ning G, Bascaramurty S, Tuor UI Metabolite changes in neonatal rat brain during and after cerebral hypoxia-ischemia: a magnetic resonance spectroscopic imaging study. NMR Biomed 1999;12:31-38.

125. Beckmann N. High resolution magnetic resonance angiography non-invasively reveals mouse strain differences in the cerebrovascular anatomy in vivo. Magn Reson Med 2000;44:252258.

126. Illanes S, Zhou W, Heiland S, Markus Z, Veltkamp R. Kinetics of hematoma expansion in murine warfarin-associated intracerebral hemorrhage. Brain Res 2010;1320:135-142.

127. Knight RA, Han Y, Nagaraja TN, et al. Temporal MRI assessment of intracerebral hemorrhage in rats. Stroke 2008;39:2596-2602.

128. Goetz P, Blamire A, Rajagopalan B, et al. Increase in apparent diffusion coefficient in normal appearing white matter following human traumatic brain injury correlates with injury severity. J Neurotrauma 2004;21:645-654

129. Stoffel M, Blau C, Reinl H, et al. Identification of brain tissue necrosis by MRI: validation by histomorphometry. J Neurotrauma 2004;21:733-740.

130. Mac Donald CL, Dikranian K, Bayly P, Holtzman D, Brody D. Diffusion tensor imaging reliably detects experimental traumatic axonal injury and indicates approximate time of injury. J Neurosci 2007;27:11869-11876.

131. Mac Donald CL, Dikranian K, Song SK, et al. Detection of traumatic axonal injury with diffusion tensor imaging in a mouse model of traumatic brain injury. Exp Neurol 2007;205:116-131.

132. Van Putten HP, Bouwhuis MG, Muizelaar JP, Lyeth BG, Berman RF. Diffusion-weighted imaging of edema following traumatic brain injury in rats: effects of secondary hypoxia. J Neurotrauma 2005;22:857-872.

133. Schuhmann MU, Stiller D, Skardelly M, et al. Metabolic changes in the vicinity of brain contusions: a proton magnetic resonance spectroscopy and histology study. J Neurotrauma 2003;20:725-743.

134. Schuhmann MU, Stiller D, Skardelly M, et al. Long-time in-vivo metabolic monitoring following experimental brain contusion using proton magnetic resonance spectroscopy. Acta Neurochir Suppl 2002;81:209-212. 
135. Tsai EC, van Bendegem RL, Hwang SW, Tator CH. A novel method for simultaneous anterograde and retrograde labeling of spinal cord motor tracts in the same animal. J Histochem Cytochem 2001;49:1111-1122.

136. Raineteau O, Fouad K, Bareyre FM, Schwab ME. Reorganization of descending motor tracts in the rat spinal cord. Eur J Neurosci 2002; 16:1761-1771.

137. Rosenzweig ES, McDonald JW. Rodent models for treatment of spinal cord injury: research trends and progress toward useful repair. Curr Opin Neurol 2004;17:121-131.

138. Nevo U, Hauben E, Yoles E, et al. Diffusion anisotropy MRI for quantitative assessment of recovery in injured rat spinal cord. Magn Reson Med 2001;45:1-9.

139. Lawrence J, Stroman PW, Bascaramurty S, Jordan LM, Malisza KL. Correlation of functional activation in the rat spinal cord with neuronal activation detected by immunohistochemistry. Neuroimage 2004;22:1802-1807.

140. Keen CL, Ensunsa JL, Clegg MS. Manganese metabolism in animals and humans including the toxicity of manganese. Met Ions Biol Syst 2000;37:89-121.

141. Hirakawa K, Naruse S, Higuchi T, et al. The investigation of experimental brain tumours using 31P-MRS and 1H-MRI. Acta Neurochir Suppl (Wien) 1988;43:140-144.

142. Gyngell ML, Els T, Hoehn-Berlage M, Hossmann KA. Proton MR spectroscopy of experimental brain tumors in vivo. Acta Neurochir Suppl (Wien) 1994;60:350-352.

143. Phuong LK, Allen C, Peng KW, et al. Use of a vaccine strain of measles virus genetically engineered to produce carcinoembryonic antigen as a novel therapeutic agent against glioblastoma multiforme. Cancer Res 2003;63:2462-2469.

144. Thu MS, Najbauer J, Kendall SE, et al. Iron labeling and pre-clinical MRI visualization of therapeutic human neural stem cells in a murine glioma model. PLoS One 2009;4: e7218.

145. Howe FA, Robinson SP, McIntyre DJ, Stubbs M, Griffiths JR. Issues in flow and oxygenation dependent contrast (FLOOD) imaging of tumours. NMR Biomed 2001;14:497-506.

146. Giannini C, Sarkaria JN, Saito A, et al. Patient tumor EGFR and PDGFRA gene amplifications retained in an invasive intracranial xenograft model of glioblastoma multiforme. Neuro Oncol 2005;7:164-176.

147. Jost SC, Hope A, Kiehl E, et al. A novel murine model for localized radiation necrosis and its characterization using advanced magnetic resonance imaging. Int J Radiat Oncol Biol Phys 2009;75:527-533.

148. Kato Y, Okollie B, Artemov D. Noninvasive 1H/13C magnetic resonance spectroscopic imaging of the intratumoral distribution of temozolomide. Magn Reson Med 2006;55:755-761.

149. Kato Y, Holm DA, Okollie B, Artemov D. Noninvasive detection of temozolomide in brain tumor xenografts by magnetic resonance spectroscopy. Neuro Oncol 2010;12:71-79.

150. Pirko I, Fricke ST, Johnson AJ, Rodriguez M, Macura SI. Magnetic resonance imaging, microscopy, and spectroscopy of the central nervous system in experimental animals. NeuroRx $2005 ; 2: 250-264$. 